\title{
Acción y reacción: del avance en la pluralidad al retroceso en los derechos adquiridos
}

\section{POR MARIANA GUADALUPE CATANZARO ROMÁN (*)}

\begin{abstract}
Sumario: I. Introducción.- II. La iglesia católica y la educación pública.- III. La iglesia católica y el derecho de familia: los registros civiles.- IV. La educación pública - un nuevo capítulo.- V. Sostén económico de un solo credo: la iglesia católica.- VI. Comienzo de un nuevo capítulo en las relaciones entre iglesia y Estado: el Papa es argentino.- VII. El nuevo Código Civil y Comercial.- VIII. Las posiciones conservadoras: católicos y protestantes se manifiestan conjuntamente.IX. Conclusiones.- X. Bibliografía.
\end{abstract}

Resumen: este artículo se refiere a las desventajas que traen, tanto en integración como en igualdad, las relaciones entre iglesia y Estado. El artículo hace un breve recorrido histórico y normativo por la relación entre el Estado argentino y la iglesia católica, y analiza la situación actual, en la que hay un reafianzamiento de estas relaciones, ahora engrosado por el ala conservadora del protestantismo.

Palabras claves: Derechos Humanos - religión - Estado - retroceso

Action and reaction: From the advancement in plurality to a setback in acquired rights

Abstract: the present article refers to the disadvantages both in integration and equality provoked by the relations between church and state. The article briefly summarizes the relations between the Argentinean State and the Catholic Church referring norms and history, while analyzing the current state of affairs, in which there seems to be a reinforcement of these relations, now strengthened by the conservative wing of Protestantism.

Keywords: Human Rights - religion - state - setback

(*) Prof. Adjunta interina Introducción al Derecho, Facultad de Ciencias Jurídicas y Sociales, Universidad Nacional de La Plata, UNLP. Doctora Cum Laude en Derechos Humanos, Universidad Carlos III de Madrid. 


\section{Introducción}

La historia argentina ha estado marcada por una relación por lo menos cuestionable con las religiones, particularmente la iglesia católica. Mucho se ha escrito sobre este tema (1). Aunque la separación nunca ha sido completa, los acontecimientos sociales han hecho que en algunas épocas sea más cercana (notablemente, durante las dictaduras militares) y en otras más lejana.

Lo cierto es que la producción legislativa en los diferentes momentos históricos de lejanía y cercanía con la iglesia católica varía trascendentalmente. Cuando los referentes políticos están distanciados de las autoridades políticas ocurre que las normas que se crean tienden a la integración, a la pluralidad y a la omnicomprensión. En cambio, cuando al contrario se hallan cercanos las normas se distancian de estos objetivos.

Este artículo describirá, pretendidamente, la acción y la reacción producidas en cuanto a los derechos y el ejercicio de ellos, no sin antes rever qué posiciones tienen los órganos deliberativos ejecutivos y judiciales en la cuestión de los derechos humanos que "preocupan" al sector eclesial.

Si bien el objeto de este artículo recorrerá las problemáticas — particularmente legislativas - que ha traído la falta de laicidad estatal en estos últimos años, tal recorrido no tiene sentido aislado. Se requiere de una breve contextualización de los problemas que esta falta ha traído en el pasado.

Evidentemente, algunos gobiernos se han posicionado más cerca del ideario católico, y otros han sido más lejanos. Sin embargo, la historia muestra que ninguno ha sido completamente ajeno a la influencia de las pretensiones de la iglesia católica. Se puede analizar los momentos de cercanía y de lejanía en las normas que cada gobierno ha sancionado. Algunas de estas normas han quitado la influencia de la iglesia del ámbito civil (por supuesto, no sin una reacción de parte de ella), mientras que otras la han colocado en un lugar privilegiado.

\section{La iglesia católica y la educación pública}

Entre las normas que han tendido a alejar la influencia de la iglesia del ámbito civil podemos mencionar a la Ley de Educación Común 1.420, sancionada en 1884 durante la presidencia de Roca. Hasta la sanción de esta ley de educación, la iglesia católica conservaba el monopolio del saber, dirigiendo o secundando la totalidad de los colegios, y dejando a los protestantes con la obligación de enviar

(1) Notablemente, Horacio Verbitsky, Loris Zanatta, Miranda Lida y Fortunato Mallimaci. Además, esta autora ha escrito su tesis de doctorado sobre este tema. 
a sus hijos a sitios donde se les brindaba educación religiosa distinta de la que recibían en sus hogares.

Siendo que la educación era en realidad un medio para inculcar la religión católica a los niños, y a los padres a través de los niños, la iglesia tuvo un especial interés en conservar ese rol. El contenido por esta ley fue un motivo constante de lucha para la iglesia católica, y lo continúa siendo hoy(2). En 1943, durante la presidencia de facto de Ramírez, se extendió por decreto la educación religiosa a todas las escuelas públicas. Este decreto fue derogado por la ley 14.401 de 1955, sancionada en los últimos meses de la segunda presidencia de Perón.

En 1956 el presidente de facto Aramburu restituyó la ley 1.420, lo cual trajo roces con la iglesia. Actualmente, los abogados y profesores de la Universidad de Buenos Aires, Marcelo Alegre y Roberto Gargarella han denunciado la derogación del artículo 8 de la ley 1.420, que sostenía la educación pública laica. Efectivamente, en Argentina, debido a la cantidad de leyes sancionadas, se ha planteado la necesidad de renumerar las leyes, quitando aquellas contradictorias y derogando aquellas redundantes. Este ha sido el caso de la ley 1.420, que ha sido modificada parcialmente por la ley 19.161 y derogada parcialmente por la ley 22.221, ninguno de los cuales hace referencia a la educación laica. Sin embargo, la ley 1.420 ha sido derogada en su totalidad en 2014 (Debate por la derogación de la ley 1.420, 2015). Esto ha pasado casi inadvertido para el universo jurídico.

\section{La iglesia católica y el derecho de familia: los registros civiles}

Otras de las normas de interés para la iglesia católica han sido las que regulan los registros civiles. Antes de la creación de los registros civiles, el registro de nacimientos, defunciones y casamientos se llevaban a cabo en las iglesias. Luego se crearon los registros civiles, pero la ley de matrimonio civil es todavía posterior. Hasta ese entonces, quienes no adherían a las prácticas religiosas católicas, debían vivir en concubinato y sin regulación alguna (Un poco de historia del Registro Civil, 2016).

La ley 2393 "Ley de matrimonio civil", sancionada en 1888, también durante la presidencia de Roca fue la que quitó las funciones de registro de matrimonio civil a la iglesia católica. Cumplían los curas la función de celebrarlos e inscribirlos, no sin antes bautizar y confirmar a los contrayentes y testigos.

(2) Como se puede ver en los casos de Salta y Mendoza. 
El matrimonio civil buscaba incluir a una minoría: los inmigrantes de otras religiones o de ninguna. La iglesia sostenía que era "el fin de la familia", que "atentaba contra el orden natural" y que habría "resultados funestos" para la sociedad.

En idéntico sentido, las inscripciones de los nacimientos dejaron de hacerse en las iglesias. Curiosamente, quedaron algunos resabios de esta práctica: el Código velezano contenía una clasificación de los hijos (naturales, adulterinos, incestuosos, sacrílegos) que respondía directamente a dogmas católicos. Si bien esta clasificación fue quitada completamente por la ley 23.264 de 1985, ya en 1954 la ley 14.367 había atenuado sus alcances, por ejemplo, prohibiendo que el "tipo" de hijo se asentara en el certificado de nacimiento (Feito Torrez, 2016). Muchos años antes, Ramón Cárcano escribió una tesis doctoral en la que se oponía a esta clasificación. La respuesta de las autoridades católicas no se hizo esperar. Emitieron una carta pastoral, curiosamente en el marco del debate de la ley 1420, donde sostenían que la tesis de Cárcano estaba llena de errores anticatólicos y antisociales. La "igualdad absoluta de los hijos legítimos con los hijos adulterinos y sacrílegos, en contra de los sagrados cánones" es consecuencia de "calificar el matrimonio de simple rito o ceremonia, como si no fuera un gran sacramento instituido".

Por supuesto, la ley de divorcio vincular sancionada en 1986 provocó un enorme enfrentamiento entre las autoridades católicas y el presidente Alfonsín. En rigor, el primer intento de ley de divorcio vincular tuvo lugar en 1954. Esta ley, 14.394, estuvo en vigencia solo pocos meses, hasta que Perón fue derrocado del gobierno. Cuando Lonardi asumió el gobierno, la Conferencia Episcopal pidió la anulación de la ley de divorcio. El cardenal Caggiano Sostuvo que era necesario que el gobierno defendiera los "derechos de la iglesia". Lo propio ocurrió en 1986, cuando la iglesia movilizó a 40.000 personas frente a la catedral metropolitana en contra del divorcio vincular (Prieto, 1986).

El debate en cuanto a las relaciones de familia no ha aminorado, sino que tiene un capítulo reciente: la iglesia católica no claudica en sus intenciones de digitar los espacios que consideraba propios. Por ello, pese a la sanción de las leyes que mencionamos, sigue emitiendo sus opiniones sobre relaciones de familia, planificación familiar, educación y demás. Por supuesto, no ocasiona ningún perjuicio la sola opinión; sí, en cambio, que las manifestaciones de sus representantes sean con pretensiones de veracidad y univocidad.

En 2006 referentes de la iglesia católica se opusieron a la Ley 26.130, Régimen para las Intervenciones de Contracepción Quirúrgica, más conocida como "ley de ligadura de trompas". Según el obispo de La Plata, Aguer, la ley está orientada a "impedir que los pobres tengan hijos" ("La iglesia dice que la anticoncepción quirúrgica sería una 'mutilación”', 2006). 
Por supuesto, la Ley 26.618 de Matrimonio Igualitario mantuvo ocupada a la cúpula católica. Además de la manifestación frente al Senado, la iglesia no sólo se encargó de llamar a los legisladores, sino que se reunió con varios de ellos y llevó abogados propios para darles a los legisladores "argumentos jurídicos" para votar en contra (De Vedia, 2010).

En 2012 las autoridades católicas se opusieron también a la Ley 26.742 de Muerte Digna. Algunos obispos se mostraron sorprendidos de que el Estado no los haya consultado sobre este tema, mientras que otros opinaron que la ley fomenta "adelantar" la muerte de los seres queridos en vez de encargarse de cuidarlos (Críticas de la Iglesia, 2007).

De la misma manera que referentes católicos se expresarían nuevamente sobre la educación religiosa impartida en escuelas públicas, de ellos hablaremos en el próximo apartado.

\section{La educación pública - un nuevo capítulo}

Si bien nos referimos antes a ese proceso de universalización de la educación al hacerla pública, gratuita y laica, un nuevo capítulo se abre al respecto en 2006, durante la presidencia de Néstor Kirchner, cuando se sancionó la ley 26.206, Ley de Educación Sexual en el Ámbito Escolar, que recibió duras críticas de parte de la iglesia católica (Es ley la educación sexual, 2006).

El lector informado advertirá la vigencia del conflicto en torno a la implementación de la Ley de educación sexual Integral, tal y como veremos más adelante.

Los sectores más reaccionarios de la sociedad, pero sobre todo católicos, protestantes y evangélicos se unirán contra la implementación de la ley y pretenderán su suspensión aun 12 años después de su promulgación (Rubin, 2018; Kane, 2018). Los periódicos de las provincias del interior del país reflejan que el debate se exacerba aún más.

Será permanente en estos tiempos la intromisión de las iglesias en asuntos que consideran dentro de su alcance. Más aun, gran parte de los credos, aunque no todos los fieles de las denominaciones (hay que decirlo) se opondrán a normas de este tipo.

En especial la iglesia católica - a través de sus referentes- se ha pronunciado sobre asuntos de los más diversos, y como si se tratase de un derecho adquirido y un rol protagónico vitalicio, pretende hacer uso de su voz adoctrinadora. 
Sin irnos mucho tiempo atrás la ley de medios reflejaba ese lugar preferencial a la divulgación de ideas y dogmas de la iglesia católica.

En 2009 se aprobó la ley 26.522, conocida como "Ley de Medios", que procuró actualizar el asunto de los medios principalmente con ánimo de que más voces se puedan oír. Sin embargo, la amplitud de participación no tuvo en cuenta la variedad religiosa y de modo grosero adjudicó a la iglesia católica espacios de comunicación muchísimo más numerosos que a los pueblos originarios y casi los mismos que a las Universidades (Pochit, 2015).

Otro evento que trascendió fue la medida expresa de la jueza porteña Elena Liberatori hizo lugar a una medida cautelar para que capellanes y religiosas que trabajan en hospitales públicos porteños tengan la "prohibición expresa" de difundir datos sobre pacientes y dispuso que "únicamente" brinden ayuda espiritual a las personas que lo requieran.

El motivo de tal pronunciamiento fue un escrache a una mujer víctima de trata de personas, que habiendo sido violada deseaba practicarse un aborto, y sufrió por esto una manifestación agresiva en la puerta de su casa. El capellán del Hospital Ramos Mejía, habría transmitido a una asociación antiabortista los datos de una mujer. El recurso fue presentado por la legisladora María Rachid que, como parte de la misma presentación ante la jueza, reclamó que se declare la inconstitucionalidad de la ordenanza 38.397, aprobada durante la última dictadura cívico militar, que otorga privilegios a curas y monjas de la iglesia católica frente a otros cultos para cumplir funciones en hospitales públicos y hogares de la ciudad (Perelló, 2013).

Como venimos resaltando, el dilema constante que se vislumbra en el Estado argentino es que en ocasiones pretendemos ser laicos, que todos los credos tengan la misma posición en cuanto a las diferentes religiones y se dicten normas omnicomprensivas. Al contrario, en otras ocasiones se les otorga a las religiones, en especial a la católica, un lugar de privilegio. Evidencia del lugar preferencial del catolicismo es que todos, absolutamente toda la población (creyentes, no creyentes, católicos y no católicos, ateos agnósticos) sostenemos con nuestros impuestos el culto católico.

\section{Sostén económico de un solo credo: la iglesia católica}

El culto católico es el único sostenido económicamente por el Estado. El resto de denominaciones o confesiones solo recibe exenciones impositivas. Los referentes de la iglesia católica, si bien han manifestado su conformidad y disconformidad con las diferentes medidas de gobierno, nunca han dejado de recibir las asignaciones previstas en el ordenamiento jurídico. 
Estas asignaciones se han instrumentado mediante leyes. Por ejemplo, la ley 21.540 de 1977 , que otorga a obispos un sueldo estatal que corresponde al $70 \%$ del sueldo de un juez de primera instancia (3); la ley 21.950 de 1979, que otorga a obispos y arzobispos un sueldo equivalente al $80 \%$ del sueldo de un juez de primera instancia; la ley 22.160 de 1980, que otorga asignaciones a párrocos fronterizos; el decreto 1928/80 del mismo año extiende esta asignación a otros párrocos; la ley 22.430/81, sancionada el 16 de marzo de 1981, derogada por ley 23.966, artículo $11^{\circ}$, y restablecida en su vigencia por ley 24.019, artículo $3^{\circ}$ establecía una asignación mensual vitalicia para Sacerdotes Seculares del Culto Católico Apostólico Romano no amparados por un régimen oficial de previsión o de prestación no contributiva; la ley 22.552, del 22 de marzo de 1982 sostiene que en caso de que el obispado, arzobispado o vicariato esté vacante, el beneficio otorgado por la ley 21.950 se pagará al obispado, arzobispado o vicariato; los beneficios económicos no incluyen solamente a aquellos ministros en funciones, sino que se extienden, además, a los individuos en formación religiosa. Así lo establece la ley 22.950, del 14 de octubre de 1983; el decreto 1.991/80 de fecha 19 de septiembre de 1980, por el cual el Estado otorga pasajes sin costo para los ministros, a través del Ministerio de Exteriores y Culto; y la 21.745, del 10 de febrero de 1978, conocida como "Ley de Cultos", que se sancionó con la excusa de llevar datos estadísticos de las religiones no católicas pero que vigilaba y controlaba los cultos que no se integraban al católico. Estas leyes que traemos fueron sancionadas en el período 1976-1983, que fue particularmente prolífero en normas a favor de la iglesia católica. Esto no quiere decir que no se hayan sancionado normas a favor de la iglesia anteriormente. Pero la extensión de este texto no nos permite mencionarlas todas (4). Esto tampoco quiere decir que las normas que han privilegiado a la iglesia católica solo se han creado durante gobiernos de facto. De hecho, la ley 24.483, sancionada en 1995, facilita el trámite de inscripción de dos instituciones dependientes de la iglesia católica a fin de obtener su persona jurídica; el decreto 491/95 de 1995 establece que la disposición de bienes entre los Institutos de Vida Consagrada, que comparte con la iglesia su persona jurídica por ser parte de ella, pueden hacerse sin intervención del Estado, sino simplemente mediante arreglos interno; el decreto 448/96 permite simplificar el trámite constitutivo de las instituciones presentando un documento sintetizado del acta; en 1998 se sancionó el decreto 1233/98, que establece que ya no es competencia del Estado entregar las credenciales a ministros religiosos católicos, sino que la iglesia se encargará de hacerlo.

(3) La relación entre un obispo y un funcionario público queda demostrada en esta ley.

(4) Para un análisis más detallado puede verse de Catanzaro Román, M. G., Relaciones entre iglesia y Estado argentino: un análisis desde la perspectiva de los Derechos Humanos, tesis doctoral. 


\section{Comienzo de un nuevo capítulo en las relaciones entre iglesia y Estado: el Papa es argentino}

Las relaciones entre la cúpula eclesial argentina y el gobierno de Néstor Kirchner eran realmente tensas luego de las declaraciones del monseñor Baseotto. En el año 2005, el vicario castrense acusó al entonces ministro de Salud, Ginés González García de apología del delito, por su propuesta de despenalizar el aborto, pero eligió la peor figura que podría esgrimirse en la Argentina posterior a la dictadura: dijo que el funcionario merecería que "le cuelguen una piedra de molino al cuello y lo tiren al mar" por repartir preservativos entre los jóvenes (Merece que lo tiren al mar, 2005). Ante los dichos del vicario el presidente de la Nación resolvió su expulsión (Dinatale, 2005). No ayudó a este conflicto el hecho de que el entonces Papa felicitara a Baseotto (Papa felicitó a Baseotto, 2007).

Sin embargo, un acontecimiento histórico volvería a cambiar la dinámica de la relación iglesia y Estado: la llegada de dicho cardenal al Vaticano, nada menos que como Papa. Desde entonces, las relaciones entre Estado e iglesia católica han reverdecido, y se les han agregado las relaciones con las corrientes protestantes conservadoras, llegadas al país de varios puntos de Sudamérica.

Actualmente, las relaciones con la iglesia católica no son pacíficas. De hecho, el difícil panorama político ha hecho que la iglesia retome las luchas históricas por determinados privilegios, pero con al menos dos novedades: por un lado, ya no solo se opone a la sanción de nuevas leyes, sino que obstaculiza la aplicación de leyes ya sancionadas; y por el otro, ya no arremete contra el Estado en soledad, sino que ha encontrado un aliado en algunos sectores evangélicos.

En la historia argentina, la dirigencia política ha utilizado a las religiones como formas de legitimación de poder. Por alianzas con líderes y ministros de iglesias, se intercambiaban favores estatales para aquellos que, desde el púlpito, ponderaran a distintos partidos políticos. El favor de las religiones lograba que los candidatos fueran presentados a los creyentes como "elegidos por Dios", un concepto de raíz cristiana (5), fuertemente sostenido desde la época medieval, y que mantiene raíces sutiles hasta hoy.

En este contexto, la clase política argentina quedó dividida entre buenas y malas relaciones con el Papa, al punto de que el Papa sostuviera que lo usaban para pulir su imagen política (Dovo, 2017; Usan imagen del Papa Francisco, 2013). Es curioso notar que esta declaración del Papa fue hecha en dos ocasiones: en 2013,

(5) Que es una interpretación del versículo del antiguo testamento, en Daniel 2: 21: "Él es quien cambia los tiempos y las edades; quita reyes y pone reyes; da sabiduría a los sabios, y conocimiento a los entendidos". 
a poco tiempo de su elección como sumo pontífice; y en 2017, en un año electivo en Argentina. Esto daría la impresión de que el acercamiento y alejamiento de los grupos religiosos y los grupos políticos tienen un fuerte contenido proselitista.

En rigor, no se puede decir que los grupos políticos tienen una afinidad permanente con determinado grupo religioso. Antes de que el cardenal Bergoglio fuera elegido Papa, la relación de Cristina Kirchner era más bien lejana. Durante la segunda presidencia de Cristina Kirchner se indagó a los legisladores sobre la relación entre el Estado con las confesiones religiosas: los legisladores consideraron mayoritariamente que todas deben ser tratadas de manera igualitaria. La mayoría cree que el Estado no debe sostener económicamente a los cultos, pero la subvención estatal de los colegios religiosos recibe una mayor aceptación. Casi la totalidad de los legisladores cree que las convicciones religiosas de los parlamentarios influyen en los contenidos de los proyectos de ley (Carbajal, 2012), obviamente cada legislador llegará a su cargo luego de haber pasado o no por experiencias y formaciones espirituales que se volcaran de una u otra manera en los proyectos que tratará.

Tras la asunción del Papa Francisco, Cristina Kirchner, dando una vuelta de página abrupta en su relación con Bergoglio, diría:

En mi nombre, en el del Gobierno argentino y en representación del pueblo de nuestro país, quiero saludarlo y expresarle mis felicitaciones con ocasión de haber resultado elegido como nuevo Romano Pontífice de la Iglesia Universal (Cristina felicitó a Jorge Bergoglio, 2013).

Y agregó:

Es nuestro deseo que tenga, al asumir la conducción y guía de la Iglesia, una fructífera tarea pastoral desempeñando tan grandes responsabilidades en pos de la justicia, la igualdad, la fraternidad y de la paz de la humanidad. (...) Le hago llegar a su Santidad, mi consideración y respeto (Cristina felicitó a Jorge Bergoglio, 2013).

Luego de esto la presidente visitó al Papa en varias oportunidades (CFK asistirá a la asunción de Bergoglio, 2013; Todas las fotos de la visita, 2015). A partir de entonces, el gobierno dio muestras por millones sobre su afinidad con el clero. A fines de noviembre de 2014, la presidente Cristina Kirchner recibió a la cúpula de la iglesia católica, encabezada por monseñor Emil Paul Tscherrig, y le anunció un conjunto de obras por 400 millones de pesos para refaccionar distintos templos y basílicas (Cristina recibió a la Iglesia, 2014).

Gestos similares de empatía con Bergoglio, ahora Papa Francisco, se verían en todo el país. Un tramo de una avenida de La Plata, que pasa junto a la Catedral de 
esa ciudad, fue bautizado Papa Francisco. El intendente de La Plata, Pablo Bruera, encabezó el acto y el arzobispo de La Plata y principal adversario de Bergoglio en la interna de la iglesia argentina, Héctor Aguer, bendijo la calle (En La Plata tiene avenida, 2013).

Las cercanías con las religiones no son inocuas. De los lazos entre Estado y religión sale legitimación y apoyo para el gobierno de turno, pero favores del gobierno para las iglesias. Entre estos favores se incluye la posibilidad de tener una voz preponderante en la creación o aplicación de leyes (6). Un claro ejemplo de esto se dio durante las audiencias públicas anteriores a la sanción del Código Civil y Comercial. Uno de los primeros expositores fue el representante de la cúpula católica (Nuevo Código Civil, 2012). La intervención de la iglesia católica tuvo especial impacto en la redacción del artículo 19, que no figuraba en el anteproyecto. Su inclusión trajo consecuencias jurídicas poco tiempo más adelante (Código Civil, 2013).

\section{El nuevo Código Civil y Comercial}

La ley que se modificaría, no sin confrontar con la iglesia, sería el Código Civil. La cúpula eclesiástica expresó su inquietud respecto a la vida, la familia y los derechos del niño, el temor siempre fue que el legislador se aparte de los dogmas eclesiales.

La curia se cree en condiciones de evaluarlo todo, incluso cómo el Gobierno administra el fondo de jubilaciones. Así, expresó con vigor y persistencia los temas que la preocupan: vientres alquilados, identidad de género, muerte digna, la pedofilia en la iglesia y el famoso caso Bargalló. Estos fueron algunos de los temas tratados durante la entrevista con La Nación. De manera recurrente vuelve sobre los aspectos del Código Civil que menos lo convencen: "Se privilegia mucho el derecho a tener un hijo y no el del hijo a tener padres y una familia" (Sirven, 2012).

Previamente a la sanción del Código Civil propuesto por Lorenzetti, ministro de la Corte Suprema de Justicia de la Nación, se realizaron debates, audiencias públicas para referir a su contenido. En ese contexto, académicos, sociólogos, ambientalistas, juristas y religiosos expusieron sus dudas y sugerencias ante la Comisión Bicameral en el Congreso de la Nación. En total hubo unos 50 disertantes. Monseñor José María Arancedo, arzobispo de Santa Fe y presidente de la Conferencia Episcopal Argentina sería uno de los oradores. Allí se dijo que el matrimonio se vaciaría de contenido si se le saca el deber de fidelidad, cohabitación,

(6) La voz preponderante de la iglesia católica incluye también la censura de ciertas manifestaciones artísticas, como fuera la exposición de León Ferrari en 2006, la oposición al voto femenino, la exigencia de las leyes de descanso dominical, entre otras. 
asistencia recíproca y cuidado de los hijos. Diría: "No cualquier forma de convivencia es igualmente valiosa. Por eso, preocupa la equiparación casi absoluta entre el matrimonio y las uniones de hecho".

Además de la iglesia católica, otras voces de religiosos, pidieron vanamente que el nuevo código "reconozca la diversidad de opiniones de fe" con la derogación de la ley de registro de culto (Reina, 2012).

Lo cierto es que el Código Civil vigente desde el primero de agosto de 2015 sigue teniendo la misma fórmula que el código de Vélez Sarsfield. Ahora como siempre, la iglesia católica es una persona de existencia pública. Así lo establece en su artículo 146, a la vez que en el 148 la distingue de las otras religiones, a las que clasifica como personas jurídicas privadas.

\section{Las posiciones conservadoras: católicos y protestantes se manifiestan conjuntamente}

En la actualidad, el panorama político argentino se caracteriza por una gran confusión. El complicado panorama político llevó a que candidatos a cargos políticos se alineen con distintos sectores religiosos. Parece ser una carrera por la legitimación, y en esta carrera, el voto de cada feligrés cuenta. Como contraparte, los candidatos hacen promesas cada vez más cercanas a las creencias religiosas que los apoyan, y por tanto cada vez más lejanas a la laicidad (En la misa de Moyano, 2018; Alfredo Olmedo era bendecido por evangelistas, 2018).

En estas manifestaciones de alianzas político religiosas han participado Hugo Moyano, quien asistió a una misa en Luján, dada por sacerdotes cercanos a la oposición política del gobierno de Macri. El contenido de la homilía fue llamativamente político. Otro sujeto cercano a la política es el sindicalista Juan Grabois, cercano a ambos Cristina Kirchner y al Papa, y del cual se dice que hace las veces de "vínculo" entre ellos (Cosoy, 2019; Pittaro, 2018). También el candidato presidencial Alfredo Olmedo ha declarado una abierta relación con el ala conservadora de las iglesias evangélicas, conocida como ACIERA.

ACIERA y el ala conservadora de las iglesias protestantes conservadoras merecen una mención especial en este tema. Su influencia viene de países donde las iglesias protestantes (particularmente las evangélicas y las pentecostales) han avanzado en sus relaciones políticas con los Estados. Así, algunos de estos grupos han recibido influencia de Perú y de, por supuesto, Brasil, donde el candidato abiertamente evangélico, Jair Bolsonaro, llegó a la presidencia, sobre una base de promesas hacia las iglesias protestantes. En muchos temas, la ideología de estos grupos protestantes se alinea a la de los grupos católicos conservadoras, y entre ambas se potencian (Dandan, s/f). 
Curiosamente, a la par de demandar políticas estatales que sigan los lineamientos de sus valores religiosos, ACIERA sostiene públicamente que defiende la separación iglesia y Estado (Cortez, 2017). Esta disonancia entre el decir y el hacer pareciera ser la consecuencia de confundir el ser nacional con el ser religioso. Así lo ha sostenido el pastor Rubén Proietti, que ante el gran número de personas convocadas a una marcha contra la interrupción legal del embarazo - marcha mayormente compuesta por feligreses de las iglesias miembros de ACIERA- dijo a los medios que el éxito de la marcha se debía a que "la cultura argentina es a favor de la vida" (Peiró, 2018). O lo que es lo mismo, la cultura argentina es a favor de los valores religiosos que ellos practican. Para él, la cultura argentina debería reflejarse en leyes. Esto lleva a concluir que, si sus valores religiosos son la cultura argentina, y la cultura argentina debe verterse en leyes, sus valores religiosos deben verterse en leyes. En esto, no están alejados del pensamiento católico, que históricamente ha asociado el ser argentino con ser católico (Zanatta, 1999). Lo que pretenden, parecería, es que los valores promovidos por su credo sean universalmente compartidos por todos y las leyes sean el fiel reflejo de su fe.

El caso "Castillo" —CSJN 1870/2014 "Castillo, Carina Viviana y otros c/ Provincia de Salta - Ministerio de Educación de la Prov. de Salta s/amparo" - puso en relieve los privilegios de la iglesia católica en las escuelas de educación pública de Salta. Allí, y con apoyo del Ministerio de Educación local, la iglesia católica había logrado dictar educación religiosa de doctrina netamente católica en el horario regular de clase. Un grupo de madres se opuso a que sus hijos recibieran estas enseñanzas. El resultado fue la separación y la estigmatización de sus hijos. El caso hizo su recorrido procesal y llegó finalmente, vía recurso extraordinario federal, a la Corte Suprema de Justicia de la Nación. La Corte llamó a amici curiae que aconsejaran sobre el asunto. Curiosamente, fueron más lo amici que apoyaron la posición del ministerio que los que expusieron sobre la necesidad de una educación pública laica. No debe pensarse que entre los amici por la parte del ministerio había solo funcionarios salteños y ministros católicos: hubo también ministros protestantes y personas cercanas al protestantismo, que vieron en este caso la posibilidad de llevar - así como la iglesia católica - sus doctrinas religiosas a las escuelas públicas (Abramovich opinó, 2017; Comenzó ante la Corte Suprema, 2017; La Corte Suprema resolvió, 2017). Esto, que fue presentado como un elemento librado a la discreción de la provincia de Salta, parece más bien un avasallamiento de los derechos adquiridos a través de la Ley 1420 de Educación Pública. Finalmente, la Corte entendió que la educación en las escuelas públicas debe ser laica, y que las enseñanzas religiosas no deben darse en el horario de clase regular.

Sirve el antecedente Castillo para mostrar cómo algunos grupos protestantes eligen alinearse con el catolicismo, aunque en su genética esté la protesta contra el credo mayoritario que pretende adoctrinar a todos a su fe propia. 
La educación pública no es el único ámbito en el que se puede encontrar el avance de los intereses religiosos sobre los intereses públicos, y el retroceso en materia de derechos adquiridos. Al lector o lectora de la introducción de este artículo seguramente se le vino a la mente el debate por la legalidad del aborto. Este debate reciente evidenció que allí donde entran creencias religiosas, se quita lugar para la integración (Los evangélicos, 2018; Rubin, 2018; Argentina, el país del papa Francisco, 2018).

Las exposiciones de los argumentos expuestos en los debates parlamentarios reflejaron las dos posiciones: aquellos que promovían la punibilidad del aborto, tenían sus fundamentos primordiales en la religión y en la apelación a las emociones. Los que se pronunciaban por la despenalización lo hacían desde la perspectiva de un Estado laico y desde la salud pública. La legisladora María Magdalena Odarda se refirió específicamente a este punto al sostener "Estamos en un Estado laico. Significa estar en un Estado en el que claramente se separa el ámbito político y social de la iglesia. ¿Quién marca el límite? La ley. No se está en contra de la religión: se asegura la libertad de cultos, pero en un Estado laico los legisladores tienen que hacer acciones para todos los ciudadanos" (Argentina \#8A, 2018). También la legisladora Lucía Crexell se refirió a la necesidad de separar los asuntos religiosos:

Votar por él no implica negar la existencia de algo que hace tiempo demanda atención. Es seguir creyendo que la criminalización va a eliminar aquello que deseamos que no suceda. Es desconocer que hay una fuerte demanda social que puja por sus derechos. Es seguir legislando a partir de la religión y, más allá de las creencias, creo firmemente que el Estado debe ser laico (Argentina \#8A, 2018).

Un medio incluso sostuvo que "las creencias religiosas son otro argumento que pesa fuerte, aunque muchos recuerdan que Argentina es un país laico" (El gran debate sobre el aborto, 2018).

El debate sobre el aborto había exacerbado a los creyentes y no creyentes. A tales extremos se llegó que resurgieron con una fuerza singular movimientos que promueven la separación total de la iglesia y el Estado. Concretamente promovían la apostasía. La forma de demostrar este rechazo fue, justamente, romper ese vínculo que los sectores religiosos dan por sentado: el ser nacional y el ser religioso.

Durante varias semanas, se formaron largas filas para llenar formularios de apostasía (Soriano, 2018). Esta apostasía colectiva demuestra, nuevamente, que son muchas las personas que entienden que allí donde entran los valores religiosos, pierden lugar la integración y la pluralidad. 
Como es de público conocimiento, el proyecto de interrupción voluntaria del embarazo fue finalmente rechazado en la Cámara de Senadores. A partir de este rechazo, de este signo positivo de afinidad que algunos legisladores tuvieron con los sectores religiosos que los legitiman, los sectores religiosos conservadores parecen haberse envalentonado. Prosiguieron con el rechazo a otros proyectos, notablemente el de la ley de educación sexual integral (Declaración de ACIERA sobre la Educación Sexual Integral, 2018). Estrictamente hablando, la ley de ESI existe desde 2006, pero nunca se instrumentaron los medios suficientes para que se aplicara uniformemente en todo el país. Cuando los sectores que apoyaban la ILE se tornaron hacia la ley de ESI, en un esfuerzo por impulsar su aplicación para garantizar y dar a conocer los derechos reproductivos, los sectores religiosos decidieron inmiscuirse en este asunto también, y exigir el incumplimiento contra legem de esta.

En un video publicado por el colectivo "Con mis hijos no te metas" (Video: Con mis hijos no te metas), la abogada Nadia Márquez explica tres columnas que sostienen el rechazo a la ley de ESI. La primera de ellas, que las modificaciones propuestas a la ESI excluyen a los padres de la educación sexual y moral de sus hijos. Esto es difícil de sostener, puesto que ni la ley de ESI ni las modificaciones propuestas dicen cómo deben educar los padres a sus hijos en el ámbito familiar. Es aún más difícil de sostener al considerar que el proyecto presentado ante la Cámara de Senadores menciona en sus fundamentos no una sino dos veces la necesidad de articular la educación impartida en la escuela con la de actores de diferentes ámbitos (que por supuesto incluye a los padres y a las madres) para que sea de calidad.

La segunda columna que plantea la abogada es la eliminación del ideario institucional. Dado que se ha dicho en varias ocasiones que el fin de la ley es darle calidad de orden público a la educación sexual, parece sorprendente el reclamo de la abogada, que daría la impresión de olvidarse que el derecho a la libertad religiosa - sobre el cual está cimentado el ideario institucional- no se alza por sobre el orden público, sino que encuentra su límite en él.

La tercera columna se refiere a que la ideología de género no tiene sustento científico sino meramente cultural. Aquí cabría preguntarse a qué llamamos sustento científico, porque si bien una parte de los científicos de la biología sostienen las diferencias tajantes entre hombres y mujeres, que motivan las acciones distintivas de cada género a la manera binaria, otra parte (si no mayor) de los científicos duda de esto. Otras ramas del conocimiento, la antropología, la psicología, la psiquiatría, la sociología, etc., no comparten esta concepción binaria de los géneros, por lo que decir que la ideología de género no es científica es negarles cientificidad a estas disciplinas. 
Si la educación sexual en las instituciones públicas es un derecho adquirido mediante la ley 26.206 de 2006, y la oposición a su aplicación cabal es un retroceso en materia de derechos adquiridos, también las propuestas de la plataforma electoral de Alfredo Olmedo son un claro avasallamiento a los derechos adquiridos. Así, Olmedo se pronunció, por ejemplo, a favor de quitar el matrimonio igualitario y el derecho de adopción de las parejas homosexuales (Olmedo: hay que suspender, 2018).

Téngase presente que la libertad religiosa y el derecho a recibir una educación sexual integral no son derechos antagónicos. La escuela buscará dar una formación que prevenga embarazos no deseados, abortos clandestinos, abusos sexuales, roles de género nocivos, entre otros. Y la iglesia alentará la castidad como un ideal; un ideal que, como se sabe, en la mayoría de los casos no se cumple. Sería interesante evaluar si la negativa a educación sexual, sostenida en parte por la creencia de que el mero hablar de sexualidad fomenta las relaciones sexuales entre jóvenes, no es un atentado al interés superior del niño. Negarles a los niños y a los adolescentes educación sexual por la pretensión de que así se abstendrán de tener relaciones sexuales es, en definitiva, decidir por ellos cuándo deben iniciar sus vidas sexuales. $\mathrm{O}$ empujarlos a iniciar su vida sexual a escondidas y sin la información adecuada.

Coinciden los grupos que se oponen a la implementación de la Ley de Educación Sexual Integral y los grupos antiaborto (aun en casos en que el Código penal no penaliza su práctica). Del mismo modo que la no implementación de la ESI avasalla los derechos de los niños, niñas y adolescentes a tener información sexual y planificar dicho aspecto de sus vidas sin abusos, también constituye una violación a los derechos humanos de las niñas violadas obligarlas a llevar adelante un embarazo u obligarlas a dar a luz.

Un paso más allá en el avasallamiento de derechos adquiridos es el entorpecimiento del ejercicio del permiso para aborto no punible, contemplado en el Código Penal desde 1921.

En Jujuy, se le negó la interrupción del embarazo a una niña de 12 años que había sido violada por un vecino de 60 años (Rivas Molina, 2018; Harán un aborto legal, 2019). Grupos religiosos en contra de la interrupción hicieron cuanto pudieron por frenarla. ACIERA manifestó su repudio e indignación por la decisión de someter a la niña a una cesárea en vez de dejar el embarazo seguir su curso (ACIERA y el caso de la beba de Jujuy, 2019), en tanto que un sacerdote de la iglesia católica bautizó a la criatura y la nombró Esperanza (Morales defendió la cesárea, 2019). Otro sacerdote se permitió llamar "asesinas" a quienes apoyaban la interrupción de este embarazo (Repudian los dichos, 2019). 
Un caso similar se dio en Tucumán. Allí, grupos religiosos acamparon fuera de la institución donde una niña de 11 años, violada por la pareja de su abuelo, y embarazada como resultado de tal violación, esperaba por que se respetara su deseo de interrumpir el embarazo. En este caso, se dilató el proceso casi un mes, buscando la maduración del feto. Finalmente, dos médicos externos a la institución llevaron adelante la cesárea, tras constatar que la vida de la niña corría riesgo. El arzobispo hizo pública la identidad de la niña violada, en grupos de mensajes (Leone, 2019).

El último capítulo de este retroceso es la unión del Ministerio de Salud y Desarrollo Social con las iglesias evangélicas de ACIERA. Por esta unión, se les concedió administrar una línea "0800" para asistir a mujeres con "embarazos inesperados". El ministerio acordó para esto un presupuesto de \$1.430.000 (Safatle, 2019). Finalmente, el proyecto se canceló ante la negativa de los grupos evangélicos de informar a las mujeres que llamaran sobre los casos de aborto no punible. Las dos únicas opciones que daban eran "criar a su hijo" o "darlo en adopción" (Vallejos, 2019).

\section{Conclusiones}

Este trabajo ha expuesto diferentes problemas, todos ellos entrelazados. La iglesia católica tiene un estatus preferencial: vimos que se sostiene económicamente todo su funcionamiento en el país. Ello trae aparejado dos consecuencias: la primera, que sus funcionarios - consciente o inconscientemente- se sienten con deber de rendirle cuentas a ella o sus dogmas. La contracara del mismo problema es que la iglesia católica demandará ser oída como voz preferencial sobre cualquier asunto que crea que le atañe. En segundo lugar, el problema es de índole político-jurídico: toda propuesta de separar a la iglesia del Estado es vista con rechazo, pues la figura del actual Papa es preponderante.

Diremos entonces que muchos referentes de denominaciones religiosas minoritarias (en cuanto a la cantidad de fieles) reaccionan casi con tanta arbitrariedad como la iglesia católica en asuntos que chocan con sus valores religiosos, tales como aborto o educación sexual integral. Como puede verse, si bien nos atañen los asuntos jurídicos, estos no son del todo separables de los estrictamente políticos.

Si en su faz positiva el Estado pretende con sus normas y enunciados normativos regular minuciosamente el ejercicio de la libertad de conciencia y de religión, se aleja del ideario de equilibrio que debiera mantenerse. Ya en la faz negativa, el Estado debiera abstenerse de cualquier apreciación, incitación, opinión, sostenimiento, promoción, etc. respecto a asuntos religiosos. Su abstención para opinar sobre asuntos espirituales es tan importante como lo que pueda hacer en su faz 
positiva. Esto porque la confesionalidad, contrariamente a la laicidad, favorece así el trato desigual y discriminatorio.

La Constitución Nacional y el resto del ordenamiento jurídico acarrean contradicciones entre distintas normas. Nuestro Estado en ocasiones promueve la libertad de conciencia y religión y en otros casos provee a sus habitantes de normas conforme a las prácticas de algunos creyentes solamente.

El 6 de junio de 2013 Argentina firmó la Convención Interamericana contra toda forma de discriminación e intolerancia. Allí, en el artículo 1 define "discriminar" como cualquier distinción, exclusión, restricción o preferencia, en cualquier ámbito público o privado, que tenga el objetivo o el efecto de anular o limitar el reconocimiento, goce o ejercicio, en condiciones de igualdad, de uno o más derechos humanos o libertades fundamentales consagrados en los instrumentos internacionales aplicables a los Estados partes. Aunque redundante a estas alturas, debemos señalar que el Estado que comulga con ideas religiosas deja fuera a las minorías no creyentes, así como a las minorías religiosas que no compartan les ideas con las que comulga el Estado.

En Argentina la elección de una confesionalidad ha sido en detrimento de la completa autonomía política y ello ha repercutido negativamente en la vida institucional, en especial en la producción normativa, si de operativizar derechos humanos se trata.

Un Estado que se precie de ser democrático realizará todas las acciones tendientes para que el ejercicio de los derechos sea igual en todas las circunstancias; intervendrá sólo de ser necesario, y se mantendrá al margen si con ello coopera con el aspecto más amplio de la libertad de las personas: su conciencia. En consonancia con ello sí dará lugar a la ESI, al aborto no punible y demás. El Estado no será promotor de determinadas conductas sobre la mera base de ser "religiosas" o "antirreligiosas", sino que contemplará todas las conductas posibles en su ordenamiento jurídico, de manera que incluya la mayor cantidad de cosmovisiones posible.

Con un tino singular, Zagrebelsky (2003, p. 17) sostiene: "el único contenido 'sólido' que la ciencia de una Constitución pluralista debería defender rigurosa y decididamente contra las agresiones de sus enemigos es el de la pluralidad de valores y principios". Utilizando la misma fórmula que Zagrebelsky, es posible presentar la siguiente conclusión: los valores y principios religiosos no se oponen al ordenamiento jurídico en tanto y en cuanto no se impongan como únicos y universalmente exigibles a todos, pues lo que se defiende con un rigor inclaudicable en una sociedad democrática es la autonomía de las personas. Y con cada persona, sus principios y valores intrínsecos. 


\section{Bibliografía}

Abramovich opinó que correspondía el cese de la educación religiosa obligatoria en las escuelas públicas salteñas en el horario escolar y dentro del plan de estudios (13/03/2017). Fiscales.gob.ar Recuperado de https://www.fiscales.gob.ar/ procuracion-general/abramovich-opino-que-correspondia-el-cese-de-la-educacion-religiosa-obligatoria-en-las-escuelas-publicas-saltenas-en-el-horario-escolar-y-dentro-del-plan-de-estudios/ [Fecha de consulta: 19/03/2019].

Aciera y el caso de la beba de Jujuy: 'Fue una muerte despedazada de la vida' (24/01/2019). AICA. Recuperado de http://www.aica.org/37458-aciera-el-casode-la-beba-jujuy-fue-una-muerte.html [Fecha de consulta: 24/03/2019].

Alfredo Olmedo era bendecido por evangelistas cuando el escenario se vino abajo (04/11/2018). Infobae. Recuperado de https://www.infobae.com/politi-

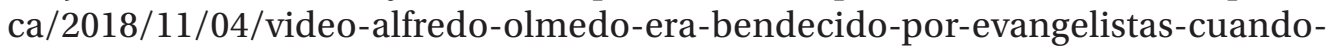
el-escenario-se-vino-abajo/ [Fecha de consulta: consultado el 20/03/2019].

Argentina \#8A: Los argumentos de los senadores a favor y en contra (09/08/2018). Resumen Latinoamericano. Recuperado de http://www.resumenlatinoamericano.org/2018/08/09/argentina-8a-los-argumentos-de-los-senadoresa-favor-y-en-contra/ [Fecha de consulta: 22/03/2019].

Argentina, el país del papa Francisco, se divide por ley sobre el aborto (11/06/2018). El Universo, Recuperado de https://www.eluniverso.com/guayaquil/2018/06/11/nota/6804389/argentina-pais-papa-se-divide-ley-sobre-aborto [Fecha de consulta: 22/03/2019].

Argentina: Usan imagen del Papa Francisco en propaganda política (31/07/2013). Perú 21. Recuperado de https://peru21.pe/mundo/argentina-imagen-papa-francisco-propaganda-politica-117844 [Fecha de consulta: 19/03/2019].

CFK asistirá a la asunción de Bergoglio (13/03/2013). Página 12. Recuperado de http://www.pagina12.com.ar/diario/ultimas/subnotas/215729-62801-201303-13.html [Fecha de consulta el 19/03/2019].

Código Civil: El Gobierno volvió a ceder ante la Iglesia y explotó el bloque K de Diputados (20/11/2013). La Política Online. Recuperado de https://www.lapoliticaonline.com/nota/nota-95338/ [Fecha de consulta: 19/03/2019].

Comenzó ante la Corte Suprema una audiencia pública en una causa en la que se debate la educación religiosa en las escuelas públicas de Salta (16/08/2017). CIJ Centro de Información Judicial. Recuperado de https://www.cij.gov.ar/nota26959-Comenz--ante-la-Corte-Suprema-una-audiencia-p-blica-en-una-causa- 
en-la-que-se-debate-la-educaci-n-religiosa-en-las-escuelas-p-blicas-de-Salta. html [Fecha de consulta: 22/03/2019].

Con mis hijos no te metas, video (s/f). Recuperado de https://www.youtube. com/watch?v=H7K14-v7TYI [Fecha de consulta: 19/03/2019].

Cristina felicitó a Jorge Bergoglio por su nombramiento (13/03/2013). La Nación. Recuperado de https://www.lanacion.com.ar/politica/cristina-felicito-a-jorge-bergoglio-por-su-nombramiento-nid1562780 [Fecha de consulta: 24/03/2019].

Cristina recibió a la Iglesia y le anunció obras por \$400 millones (28/11/2014). La Nación. Recuperado de http://www.lanacion.com.ar/1747559-cristina-recibio-ala-iglesia-y-le-anuncio-obras-por-400-millones [Fecha de consulta: 24/03/2019].

Críticas de la iglesia a la ley que autoriza la "muerte digna" (01/12/2007). La Nación. Recuperado de https://www.lanacion.com.ar/sociedad/criticas-de-laiglesia-a-la-ley-que-autoriza-la-muerte-digna-nid967129 [Fecha de consulta: 25/03/2019].

Debate por la derogación de la ley 1420 (31/07/2015). Noticias UBA, Recuperado de http://www.uba.ar/noticiasuba/nota.php?id=564 [Fecha de consulta: 15/03/2019].

Declaración de ACIERA sobre la Educación Sexual Integral (19/09/2018). Bariloche opina, Recuperado de https://www.barilocheopina.com/noticias/ 2018/09/19/37962-declaracion-de-aciera-sobre-la-educacion-sexual-integral [Fecha de consulta: 24/03/2019].

El gran debate sobre el aborto: 50 opiniones a favor y en contra (27/02/2018). Clarín. Recuperado de https://www.clarin.com/sociedad/gran-debate-aborto50-opiniones-referentes-sociales-favor_0_HkDpQIXdz.html [Fecha de consulta: 22/03/2019].

En la misa de Moyano, la Iglesia pidió cambiar el modelo económico (20/10/2018). Clarín. Recuperado de https://www.clarin.com/politica/moyanosindicatos-duros-lujan-encabezar-misa-pan-trabajo_0_LybWqky6Z.html [Fecha de consulta: 20/03/2019].

En La Plata tiene avenida (27/03/2013). Página 12. Recuperado de http://www. pagina12.com.ar/diario/elpais/subnotas/216703-62963-2013-03-27.html [Fecha de consulta: 20/03/2019]. 
Es ley la educación sexual obligatoria para las escuelas (04/04/2006). La Nación. Recuperado de https://www.lanacion.com.ar/sociedad/es-ley-la-educacion-sexual-obligatoria-para-las-escuelas-nid846380 [Fecha de consulta: 20/03/2019].

Harán un aborto legal a una niña violada: lo querían frenar la Iglesia y grupos Pro-Vida (16/01/2019). Clarín. Recuperado de https://www.clarin.com/sociedad/ negaron-aborto-legal-nena-12-anos-embarazada-23-semanas_0_3HVtktZyQ. html [Fecha de consulta: 24/03/2019].

La Corte Suprema resolvió que en Salta no podrá darse educación religiosa en las escuelas públicas en el horario escolar y como parte del plan de estudios (12/12/2017). CIJ Centro de Información Judicial. Recuperado de https://www. cij.gov.ar/nota-28821--La-Corte-Suprema-resolvi--que-en-Salta-no-podr--darseeducaci-n-religiosa-en-las-escuelas-p-blicas-en-el-horario-escolar-y-como-parte-del-plan-de-estudios.html [Fecha de consulta: 22/03/2019].

LaIglesiadicequelaanticoncepciónquirúrgicaseríauna “mutilación” (24/06/2006). Infobae. Recuperado de https://www.infobae.com/2006/06/24/262275-la-iglesiadice-que-la-anticoncepcion-quirurgica-seria-una-mutilacion/ [Fecha de consulta: 25/03/2019].

Los evangélicos a favor de la vida y en contra del aborto (06/03/2018). AICA. Recuperado de http://www.aica.org/32576-los-evangelicos-favor-de-la-vida-encontra-del-aborto.html [Fecha de consulta: 25/03/2019].

Merece "que lo tiren al mar" (19/02/2005). Página 12. Recuperado de https:// www.paginal2.com.ar/diario/sociedad/3-47505-2005-02-19.html [Fecha de consulta: 22/03/2019].

Morales defendió la cesárea de la nena violada: "Hay militantes 'verdes' que quieren que mate al bebé" (19/01/2019). Perfil. Recuperado de https://www.perfil.com/noticias/sociedad/morales-sobre-nena-violada-en-jujuy-verdes-quieren-que-mate-al-bebe-no-lo-hare.phtml [Fecha de consulta: 22/03/2019].

Nuevo Código Civil: audiencia pública con aportes y críticas (12/09/2012). El Litoral. Recuperado de https://www.ellitoral.com/index.php/diarios/2012/09/12/ politica/POLI-07.html [Fecha de consulta: 19/03/2019].

Olmedo: "Hay que suspender el matrimonio igualitario y la identidad de género" (26/11/2018). Canal 13 San Juan. Recuperado de https://www.canal13sanjuan.com/politica/2018/11/26/olmedo-hay-que-suspender-el-matrimonio-igualitario-la-identidad-de-genero-91185.html [Fecha de consulta: 24/03/2019]. 
Papa felicitó a Baseotto por cuidar el espíritu (28/04/2007). Perfil. Recuperado de https://www.perfil.com/noticias/sociedad/papa-felicito-a-baseotto-por-cuidar-el-espiritu-20070427-0058.phtml [Fecha de consulta: 20/03/2019].

Repudian los dichos de un vicario sobre la menor jujeña violada (24/01/2019). Nuevo diario de Salta. Recuperado de https://www.nuevodiariodesalta.com.ar/ noticias/provinciales-2/repudian-los-dichos-de-un-vicario-sobre-la-menor-jujenia-violada-28193 [Fecha de consulta: 24/03/2019].

Todas las fotos de la visita de Cristina a Roma y el Vaticano (07/06/2015). Perfil. Recuperado de http://www.perfil.com/politica/Todas-las-fotos-de-la-visita-de-Cristina-a-Roma-y-el-Vaticano-20150607-0025.html [Fecha de consulta: 20/03/2019].

Un poco de historia del Registro Civil de la Ciudad de Buenos Aires (1886-2016). Buenos Aires Ciudad. Recuperado de https://www.buenosaires.gob.ar/gobierno/ historia [Fecha de consulta: 24/03/2019].

Carbajal, M.(14/01/2012). ADios rogando, pero en la gente pensando. Página 12. Recuperado de http://www.pagina12.com.ar/diario/elpais/1-185463-2012-01-14. html [Fecha de consulta: 21/03/2019].

Causa: "Asociación Civil Asamblea Permanente por los Derechos Humanos, en jo 250169/50369 Asociación Civil Asamblea Permanente por los Derechos Humanos c/ Dirección General de Escuelas p/ acción de amparo p/ rec. ext. de inconstitucionalidad".

Cortez C., (16/01/2017). Algunas Aclaraciones de Conceptos Errados sobre el Accionar de ACIERA. Recuperado de http://ongonline.net/2017/01/16/algunasaclaraciones-de-conceptos-errados-sobre-el-accionar-de-aciera/ [Fecha de consulta: 20/03/2019].

Cosoy, N. (14/03/2019). ¿Cuánto y cómo influye el papa Francisco sobre la política de Argentina? France 24. Recuperado de https://www.france24.com/ es/20190313-influencia-papa-francisco-politica-argentina [Fecha de consulta: 20/03/2019].

Dandan, A. (S/f), El mercado vacante. El cohete a la luna. Recuperado de https://www.elcohetealaluna.com/el-mercado-vacante/ [Fecha de consulta: 19/03/2019].

De Vedia, M. (19/05/2010). La Iglesia enfrenta al matrimonio gay. La Nación. Recuperado de https://www.lanacion.com.ar/sociedad/la-iglesia-enfrenta-almatrimonio-gay-nid1266201 [Fecha de consulta: 25/03/2019]. 
Dinatale, M. (12/03/2005). Castigaría el Gobierno al obispo Baseotto. La Nación. Recuperado de https://www.lanacion.com.ar/cultura/castigaria-el-gobierno-al-obispo-baseotto-nid686911 [Fecha de consulta: 20/03/2019].

Dovo, L. (22/01/2017). El Papa se enojó con los políticos argentinos porque lo "usan". El doce tv. Recuperado de https://eldoce.tv/mundo/el-papa-francisco-seenojo-con-los-politicos-argentinos-porque-lo-usan-fotos-redes-sociales_33713 [Fecha de consulta: 20/03/2019].

Feito Torrez, M. V. (2016). La "maldad de los padres sobre los hijos": un recorrido por el concepto de filiación en Argentina. Derecho, Estado y Religión, Vol. 2 Núm. 2.

Kane, G. (26/09/2018). Por qué es necesaria una reforma de la ley de educación sexual integral. Infobae. Recuperado de https://www.infobae.com/opinion/2018/09/26/por-que-es-necesaria-una-reforma-de-la-ley-de-educacionsexual-integral/ [Fecha de consulta: 25/03/2019].

Leone, E. (27/02/2019). El arzobispo de Tucumán dio el nombre de la niña que fue obligada a parir. La Izquierda Diario. Recuperado de https://www.laizquierdadiario.cl/El-arzobispo-de-Tucuman-dio-el-nombre-de-la-nina-que-fue-obligada-a-parir [Fecha de consulta: 25/03/2019].

Ley 19.161, “educación”, publicada el 10/08/1971.

Ley 22.221, "derogación parcial", publicada el 05/05/1980 en el Boletín Oficial 14/05/1980-ADLA 1980 - B, 1042.

Nino, Carlos S. (1992). Fundamentos de Derecho Constitucional: análisis filosófico, jurídico y politológico de la práctica constitución. Buenos Aires: Astrea.

Peiró, C. (18/08/2018). Rubén Proietti: Lo del Obelisco fue multitudinario porque la cultura argentina es a favor de la vida. Infobae. Recuperado de https:// www.msn.com/es-ar/noticias/otras/rub\%C3\%A9n-proietti-\%E2\%80\%9Clo-delobelisco-fue-multitudinario-porque-la-cultura-argentina-es-a-favor-de-la-vida/ ar-BBM4Ttx [Fecha de consulta: 25/03/2019].

Perelló, C. (18/01/2013). Límites a los sacerdotes en los hospitales. Página 12. Recuperado de http://www.paginal2.com.ar/diario/sociedad/3-212105-2013-01-18. html [Fecha de consulta: 19/03/2019].

Pittaro, E. (20/09/2018). ¿Quién es Juan Grabois, el activista al que presentan como "el amigo del Papa"? Aleteia. Recuperado de https://es.aleteia. org/2018/09/20/quien-es-juan-grabois-el-activista-al-que-presentan-como-elamigo-del-papa/ [Fecha de consulta: 20/03/2019]. 
ACCIÓN Y REACCIÓN: DEL AVANCE EN LA PLURALIDAD AL RETROCESO EN LOS DERECHOS ADQUIRIDOS - MARIANA GUADALUPE CATANZARO ROMÁN (PP. 271-294)

Pochit, S. y Astiazarán, J. M. (18/04/2015). La Ley de Medios se aplica como Dios manda. La Izquierda Diario. Recuperado de http://www.laizquierdadiario.com/ La-Ley-de-Medios-se-aplica-como-Dios-manda [Fecha de consulta: 25/03/2019].

Prieto, M. (7/07/1986). La Iglesia se moviliza contra el proyecto de Alfonsín de legalizar el divorcio en Argentina. El País. Recuperado de https://elpais.com/ diario/1986/07/07/internacional/521071214_850215.html [Fecha de consulta: 29/03/2019].

Prieto Sanchís (2013). El constitucionalismo de los derechos: Ensayos de filosofía jurídica. Madrid: Trotta.

Reina, L. (24/08/2012). Críticas de la Iglesia al nuevo Código Civil en el Congreso. La Nación. Recuperado de http://www.lanacion.com.ar/1501959-criticas-dela-iglesia-al-nuevo-codigo-civil-en-el-congreso [Fecha de consulta: 29/03/2019].

Rivas Molina, F. (24/05/2018). Una niña de 10 años violada y embarazada agita el debate sobre el aborto en Argentina. El País. Recuperado de https://elpais.com/ internacional/2018/05/24/argentina/1527191220_914624.html [Fecha de consulta: 25/03/2019].

Rubin, S. (03/10/2018). La Iglesia pide límites a la educación sexual en los colegios. Clarín. Recuperado de https://www.clarin.com/sociedad/iglesia-pideeducacion-sexual-limite-hacer-quedar-embarazada_0_MkgB3v0Zx.html [Fecha de consulta: 27/03/2019].

Rubin, S. (9/08/2018). Aborto: la Iglesia, el actor clave que logró frenar la ley. Clarín. Recuperado de https://www.clarin.com/sociedad/aborto-iglesia-actorclave-logro-frenar-ley_0_rk1CDLuH7.html [Fecha de consulta: 22/03/2019].

Safatle, P. (11/03/2019). Cómo funcionará el 0800 "pro-vida" para asistir a mujeres con embarazos inesperados. Infobae. Recuperado de https://www.infobae. com/sociedad/2019/03/11/como-funcionara-el-0800-pro-vida-para-asistir-amujeres-con-embarazos-inesperados/ [Fecha de consulta: 27/03/2019].

Sirven, P. (05/08/2012). La Iglesia no va a hacer oposición, pero tampoco va a calar su voz. La Nación. Recuperado de http://www.lanacion.com.ar/1496036-laiglesia-no-va-a-hacer-oposicion-pero-tampoco-va-a-callar-su-voz [Fecha de consulta: 25/03/2019].

Soriano, F. (08/08/2018). Apostasía colectiva: largas filas en el lado verde para renunciar a la Iglesia Católica. Infobae. Recuperado de https://www.infobae.com/ sociedad/2018/08/08/apostasia-colectiva-largas-filas-en-el-lado-verde-para-renunciar-a-la-iglesia-catolica/ [Fecha de consulta: 24/03/2019]. 
Vallejos, S. (16/03/2019). Abortaron el 0800 antiderechos. Página 12. Recuperado de https://www.pagina12.com.ar/181309-abortaron-el-0800-antiderechos [Fecha de consulta: 27/03/2019].

Zagrebelsky, G. (2003). El derecho dúctil. Ley, derechos, justicia (Traducción de Marina Gascón). $5^{\text {a }}$ ed. Madrid: Trotta.

Zanatta, L. (1999). Perón y el mito de la nación católica. Iglesia y Ejército en los orígenes del peronismo (1943-1946). Buenos Aires: Sudamericana.

Fecha de recepción: 01-04-2019 Fecha de aceptación: 24-04-2019 